\title{
Opening snap and isovolumic relaxation period in relation to mitral valve flow in patients with mitral stenosis Significance of A2-OS interval
}

\author{
D. Kalmanson, Colette Veyrat, A. Bernier, S. Witchitz, and P. Chiche \\ From the Departments of Cardiology, Fondation A. de Rothschild and Hopital Tenon, Paris, France
}

In 15 patients with pure or predominant mitral stenosis and in a control group of 11 patients without mitral stenosis the blood flow velocity through the mitral valve orifice was recorded by means of a directional Doppler ultrasound velocity catheter introduced transeptally and positioned in the orifice of the mitral valve. $A$ simultaneous surface phonocardiogram was obtained. The timing of the mitral opening snap in relation to the blood velocity record of the flow through the valve supported the hypothesis that the opening snap is due to a sudden tensing of the valve leaflets by the chordae tendineae. Determination of the exact time of mitral valve opening, made possible by the blood velocity record, led to the division of the classical A2-OS interval (aortic valve closure to opening snap) into two components representing respectively the diastolic isovolumic relaxation period and the time of excursion of the mitral valve cusps. The durations of the isovolumic relaxation period were compared with those in the control patients and were found to correlate with the severity of the mitral stenosis, whereas those of the excursion time of the mitral cusps were influenced by the presence or absence of mitral valve calcification.

Though the importance of the mitral opening snap has been universally recognized, it is piquant to note that 150 years after it was first described (Bertin, 1824) controversy persists over its diagnostic value, mode of production, and time relationship to the isovolumic relaxation period of the left ventricle. It had been considered pathognomonic of mitral stenosis until the possibility was raised of its occurrence in other conditions such as mitral regurgitation (Nixon, Wooler, and Radigan, 1960; Perloff and Harvey, 1962), ventricular septal defect, or persistent ductus arteriosus (Luisada, 1953, 1965; Millward, McLaurin, and Craige, 1973)-that is, in conditions which have in common an excess flow through the mitral valve.

Its genesis has been continually questioned. Many mechanisms have been suggested-among others, two-phase filling of the left ventricle (Bouillaud, 1835) and asynchrony of aortic and pulmonary valve closure (Duroziez, 1862)-until

Received 1 April 1975.
Potain, in Rouchès's thesis (Rouchès, 1888), coined the term claquement d'ouverture (opening snap), thereby implying a sudden stretching of the valve leaflet restrained in its excursion by the shrunken, stiff, chordae tendineae. This hypothesis was later supported by the well documented mechanographic correlation studies of Wolferth and Margolies (Margolies and Wolferth, 1932) and eventually was generally accepted. Additional evidence for such a mechanism was provided by cineangiographic studies of the mitral valve (Ross, Criley, and Morgan, 1961; Ross and Criley, 1964; McCall and Price, 1967), which showed that the snap occurred at the time of maximum excursion of the valve leaflet but failed to demonstrate any filling of the left ventricle before the complete opening of the valve. More recently, echocardiographic recording of movements of the anterior leaflet of the mitral valve confirmed a synchrony between the snap and the completion of the rapid movement of the valve (Friedman, 1970; Millward et al., 1973). Rodbard and Libanoff (1972), on the other hand, proposed a new and entirely different mechanism, contending 


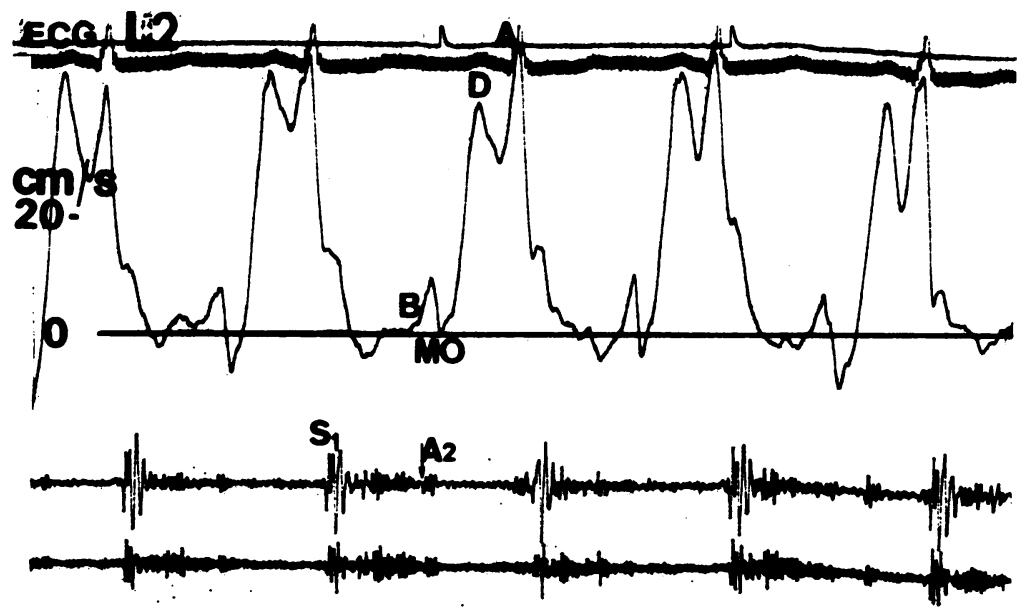

FI G. 1 Normal mitral valve flow velocity curve calibrated in $\mathrm{cm} / \mathrm{s}$. Velocities above zero.line refer to flow passing from left atrium into left ventricle, those below zero line refer to flow directed from left ventricle toward left atrium. Note inflexion point $B$ lining up with first vibrations of $A 2$, and inflexion point $M O$ at onset of ascending limb of $D$ wave (true mitral opening). During diastole note two successive waves. $D=$ initial filling wave, $A=$ atrial contraction wave. The usual precipitous negative deflection (ic) lining up with the first heart sound is missing.

that sudden closure of the valve after the initial opening was in fact responsible for the anomalous sound, which therefore should be called a 'closing snap'. In addition to these irreconcilable explanations, it was still not clear whether blood did or did not flow through the valve at the time of the snap.

Moreover, an apparent close timing relationship between the occurrence of the opening snap (OS), of the $O$ trough of the early diastolic wave of the apex cardiogram and of the crossing point of atrial and ventricular pressure curves led to the now currently accepted assumption that the time interval between the aortic component of the second heart sound and the opening snap (A2-OS) or the $O$ point of the apex cardiogram (A2-O) represented fairly well for clinical purposes the isovolumic relaxation period of the left ventricle (Taquini, Massell, and Walsh, 1940; Rappaport and Sprague, 1942; Fishleder, 1966; Legler, Benchimol, and Dimond, 1963; Coulshed and Epstein, 1963; Deuchar, 1964; Tafur, Cohen, and Levine, 1964; Benchimol and Ellis, 1967; Spodick and Kumar, 1968; Delage et al., 1971). Such an identification, however, was seriously questioned by Di Bartolo (Di Bartolo, Nuñez-Dey, and Bendezú-Prieto, 1962), Tavel (Tavel et al., 1965), Forman (Forman et al., 1967), and, more recently, Willems (Willems, De Geest, and Kesteloot, 1971).

We showed (Kalmanson et al., 1975a) the feasibility of instantaneously recording the mitral valve blood flow velocity (Fig. 1) using transepta Doppler ultrasound catheterization, and we proposed a physiological interpretation of the recorded wave form (Fig. 2). In particular, it was possible to define and measure the isovolumic relaxation period and determine the actual opening point of the mitral valve. We also studied the blood flow velocity patterns through the mitral valve in patients with mitral valve disease (Kalmanson et al., 1975b). These findings led us to study the correlation of the timing of the second heart sound and that of the opening snap in relation to instantaneous mitral valve blood flow phenomena.

\section{Patients}

A total of 15 patients ( 9 women and 6 men) ranging in age from 26 to 60 years was studied. Twelve had pure mitral stenosis and three predominant mitral stenosis associated with mitral regurgitation; six were in sinus rhythm and nine in atrial fibrillation. Routine phonocardiograms were recorded in all patients, firstly, with simultaneous carotid pulse and apex cardiogram recordings and, secondly, with routine diagnostic cardiac catheterization using the transeptal route. A Telco (St. Cloud, France) manometer for pressure measurements and a Waters (Waters, Rochester, Minnesota, U.S.A.) dye dilution apparatus to determine cardiac output were used. The patients were carefully examined for calcification of the mitral valve at fluoroscopy and subsequently at operation (6 cases) or necropsy (1 case). Nine patients had obvious calcification, six had little or none. 


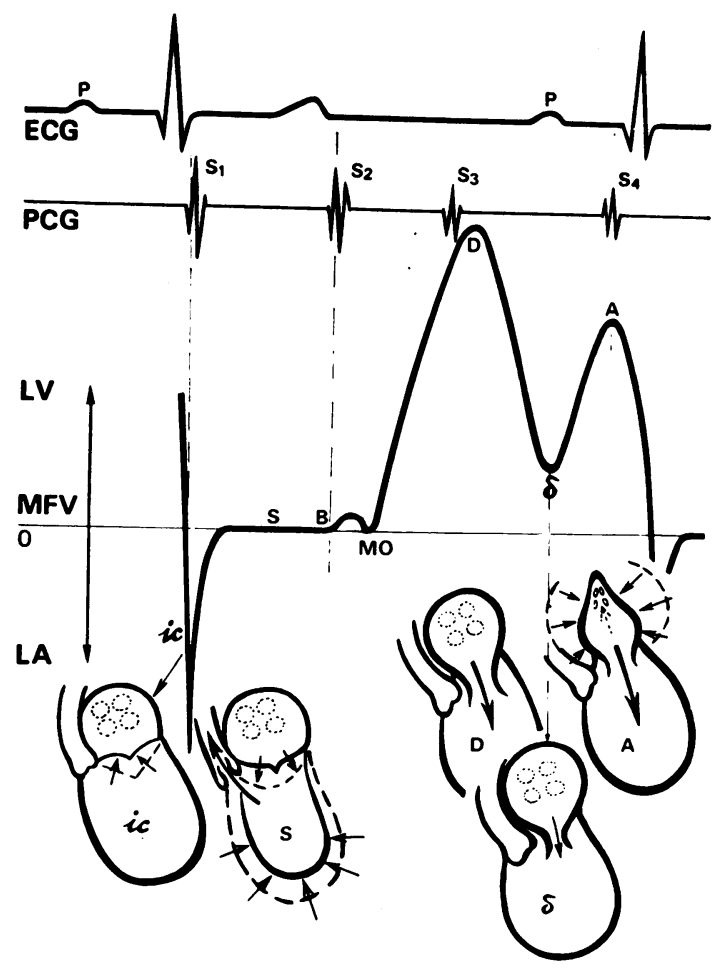

NORMAL MITRAL FLOW

FIG. 2 Physiological interpretation of mitral valve flow velocity curve. Initial negative deflection, ic, is due to bulging of mitral valve into left atrium during isometric contraction provoked by the contraction of papillary muscles and completing apposition of leaflets. Whether it is accompanied by true regurgitation is questionable. S segment along the zero line indicates absence of flow through closed mitral valve. Small segment B-MO extending from notch, synchronous with second heart sound, to onset of $D$ wave delimits isovolumic relaxation period. $D$ wave represents initial diastolic filling of left ventricle, and $A$ wave the end-diastolic filling due to atrial contraction.

\section{Classification of patients}

Patients were classified according to the severity of their stenosis: $1=$ mild, $2=$ moderate, and $3=$ severe. This classification for the pure or predominant lesion on a three-point scale was based partly on the clinical presentation (bedside and $x$-ray examination, electrocardiograph, and clinical course) and on the haemodynamic data (LA-LV pressure gradient and, particularly, a calculated mitral area of greater than $1.5 \mathrm{~cm}^{2}$ for grade 1 , between 1.5 and $1 \mathrm{~cm}^{2}$ for grade 2 , and less than $1 \mathrm{~cm}^{2}$ for grade 3 ). The haemodynamic data and classification of patients are shown in Table 1.
For comparison we studied a control group of 11 patients ( 3 women and 8 men) ranging in age from 25 to 60 years in whom mitral stenosis was ruled out in the course of routine diagnostic catheterization of the left heart. They included four patients with aortic stenosis; two with atrial septal defect, one of whom had a cleft mitral valve; two with chronic pericarditis; and three in whom the chest radiographs were abnormal but who had a normal left heart on catheterization. Diagnostic and haemodynamic data of these patients are summarized in Table 2 .

All the patients studied were free from diseases known to modify the isovolumic relaxation period, such as hypertension, moderate to severe aortic or mitral regurgitation, cardiomyopathy, or cardiac failure.

\section{Methods}

We used the directional Doppler ultrasonic catheter-tip velocimeter BV 135 Sonicaid (Sonicaid Ltd., Bognor Regis, England) (Kalmanson et al., 1972). The technique of transeptal Doppler ultrasound catheterization of the mitral valve and the physiological interpretation of the recorded curves have been discussed previously (Kalmanson et al., 1975a, b). The mitral flow velocity curves were inscribed on a four-channel 34 or a sevenchannel 81 Mingograf direct inkwriting recorder simultaneously with an ECG lead II and a frequencyselected $(25,50,100,200,400,700 \mathrm{~Hz})$ phonocardiogram at the apex using an EM 22 Elema-Schoenander microphone (chart speed $50 \mathrm{~mm} / \mathrm{s}$ ). The distance between two successive spikes (Fig. 1) equals $1 \mathrm{~s}$.

\section{Patients with mitral stenosis}

In all patients with mitral stenosis we determined the following points: A2-the first large high-frequency vibration of the aortic component of the second heart sound, checked by its relationship to the dicrotic notch of the carotid artery pulse tracing; OS-the first large high-frequency vibration of the opening snap sound on the phonocardiogram, checked by its relationship to the $\mathrm{O}$ point of the apex cardiogram; MO-the onset on the flow velocity curve of the ascending limb of the initial diastolic filling wave of the left ventricle. We measured the following time intervals: A2-MO-between the first vibration of the aortic second sound and the MO point of the flow velocity curve; MO-OSbetween the latter point and the opening snap. Three successive measurements were made for each patient and the average value was retained.

The time lag of the Sonicaid velocimeter has been shown to be about $10 \mathrm{~ms}$ (Kalmanson et al., 1972). Therefore a correction of $-10 \mathrm{~ms}$ was made for the time interval A2-MO, and of $+10 \mathrm{~ms}$ for the time interval MO-OS. All time intervals were corrected for heart rate according to the Bazett (1920) formula (x $[1 / \sqrt{\mathrm{RR}}])$.

\section{Control patients}

The A2-MO time interval was determined and mea- 
138 Kalmanson, Veyrat, Bernier, Witchitz, and Chiche

TABLE 1 Classification and haemodynamic data of 15 patients with pure mitral stenosis

\begin{tabular}{|c|c|c|c|c|c|c|c|c|}
\hline $\begin{array}{l}\text { Case } \\
\text { No. }\end{array}$ & Rhythm & $\begin{array}{l}\text { LA pressure } \\
(\mathrm{mmHg})\end{array}$ & $\begin{array}{l}L V \text { pressure } \\
(\mathrm{mmHg})\end{array}$ & $\begin{array}{l}L A-L V \\
\text { pressure } \\
\text { gradient }\end{array}$ & $\begin{array}{l}\text { Calculated } \\
\text { mitral area } \\
\left(\mathrm{cm}^{2}\right)\end{array}$ & $\begin{array}{l}C I \\
\left(l / \text { min per } m^{2}\right)\end{array}$ & $\begin{array}{l}\text { MS } \\
\text { grading }\end{array}$ & Associated lesions \\
\hline 1 & AF & $10 / 4$ & $\begin{array}{r}106 /{ }^{-4} \\
+2\end{array}$ & $5 \cdot 7$ & $1 \cdot 7$ & $2 \cdot 6$ & 1 & \\
\hline 2 & SR & $12 / 7$ & $200 / 5$ & 2 & $2 \cdot 5$ & $2 \cdot 3$ & 1 & \\
\hline 3 & SR & $17 / 10$ & $134 /^{-6} 5$ & 3 & $1 \cdot 9$ & $2 \cdot 5$ & 1 & Arrhythmias \\
\hline 4 & SR & $12 / 2$ & $97 I^{-2}+4$ & 5 & $2 \cdot 3$ & 3 & 1 & \\
\hline 5 & SR & $20 / 16$ & $104 /^{-2} 8$ & 11.5 & $1 \cdot 1$ & $2 \cdot 2$ & 2 & \\
\hline 6 & $\mathrm{AF}$ & $14 / 7$ & $108 / 2$ & 4 & $1 \cdot 2$ & 2 & 2 & TS, TR, AS, MR \\
\hline 7 & SR & $15 / 8$ & $122 \begin{array}{l}0 \\
8\end{array}$ & $6 \cdot 4$ & $1 \cdot 2$ & $2 \cdot 4$ & 2 & TS \\
\hline 8 & $\mathrm{AF}$ & $25 / 12$ & $158 / \frac{0}{12}$ & 4 & 1.6 & $3 \cdot 6$ & 2 & $\mathrm{AS}, \mathrm{AI}, \mathrm{MR}$ \\
\hline 9 & SR & $9 / 4$ & $93 / 3^{-3}$ & 4 & $1 \cdot 4$ & $2 \cdot 9$ & 2 & \\
\hline 10 & SR & $17 / 5$ & $134 /_{8}^{2}$ & 3 & 1.5 & $2 \cdot 5$ & 2 & \\
\hline 11 & SR & $20 / 14$ & $124 / \begin{array}{r}-8 \\
6\end{array}$ & 9 & 0.9 & $2 \cdot 7$ & 3 & \\
\hline 12 & SR & $22 / 10$ & $112 /^{-3} 2$ & 11 & $1 \cdot 0$ & $2 \cdot 3$ & 3 & \\
\hline 13 & $\mathrm{AF}$ & $35 / 18$ & $220 / \begin{array}{r}0 \\
10\end{array}$ & 17 & 0.4 & $1 \cdot 2$ & 3 & \\
\hline 14 & $\mathrm{AF}$ & $16 / 10$ & $100 /-2$ & 10 & 1 & $2 \cdot 5$ & 3 & AI, MR \\
\hline 15 & AF & $52 / 37$ & $146 / 0$ & 35 & 0.6 & $2 \cdot 4$ & 3 & AS \\
\hline
\end{tabular}

LA=left atrium; $L V=$ left ventricle; $C I=$ cardiac index; $M S=$ mitral stenosis; $M R=$ mitral regurgitation; $T S=$ tricuspid stenosis; $T R=$ tricuspid regurgitation; $A S=$ aortic stenosis; $A R=$ aortic regurgitation; $A S D=$ atrial septal defect. Conversion from Traditional Units to SI Units: $1 \mathrm{mmHg} \approx 0.133 \mathrm{kPa}$.

sured with the same correction for heart rate and time lag as for patients with mitral stenosis.

\section{Results}

Time relationship between opening snap and mitral valve flow velocity (Fig. $3,4,5$ )

The ascending limb of the initial diastolic filling D wave consistently showed, at a variable height, an isolated notch-that is, a small and brief $(0.01$ to
$0.03 \mathrm{~s}$ ) downward deflection or plateau synchronous with the opening snap on the phonocardiogram. The onset of this deflection started synchronously with the first vibration of the opening snap and its trough occurred, on average, usually $10 \mathrm{~ms}$ later. It was followed, with a variable delay in each patient, by a series of irregular indentations synchronous with the vibrations of the diastolic murmur recorded on the phonocardiogram. The height of occurrence (on the flow velocity trace) of the notch was greater 
TABLE 2 Haemodynamic data of 11 patients in control group

\begin{tabular}{|c|c|c|c|c|c|}
\hline $\begin{array}{l}\text { Case } \\
\text { No. }\end{array}$ & $\begin{array}{l}\text { Mean } \\
\text { LA pressure } \\
\text { (mmHg) }\end{array}$ & $\begin{array}{l}L V \text { pressure } \\
(\mathrm{mmHg})\end{array}$ & $\begin{array}{l}L A-L V \\
\text { pressure } \\
\text { gradient }\end{array}$ & $\begin{array}{l}C I \\
\left(l / \min \text { per } m^{2}\right)\end{array}$ & Diagnosis \\
\hline 16 & 10 & $136 / 8$ & 0 & 3.0 & AS \\
\hline 17 & 5 & $160 / 5$ & 0 & 3.0 & AS \\
\hline 18 & 2 & $100 / 6$ & 0 & $1 \cdot 7$ & AS \\
\hline 19 & 4 & $106 /{ }_{4}^{2}$ & 0 & $3 \cdot 1$ & $\begin{array}{l}\text { ASD with cleft mitral } \\
\text { valve }\end{array}$ \\
\hline 20 & 0 & $216 / 4$ & 0 & $4 \cdot 0$ & AS \\
\hline 21 & 8 & $108 /{ }_{6}^{0}$ & 0 & $3 \cdot 4$ & Chronic pericarditis \\
\hline 22 & 2 & $125 / 5$ & 0 & $4 \cdot 2$ & Chronic pericarditis \\
\hline 23 & 4 & $110 / 2$ & 0 & $4 \cdot 4$ & $\begin{array}{l}\text { Normal heart } \\
\text { (abnormal radiograph) }\end{array}$ \\
\hline 24 & 3 & $120 / 0$ & 0 & 4.5 & ASD \\
\hline 25 & 4 & $120 / 4$ & 0 & $4 \cdot 7$ & $\begin{array}{l}\text { Normal heart } \\
\text { (abnormal radiograph) }\end{array}$ \\
\hline 26 & 4 & $126 / 4$ & 0 & 2.5 & $\begin{array}{l}\text { Norman heart } \\
\text { (abnormal radiograph) }\end{array}$ \\
\hline
\end{tabular}

Abbreviations as in Table 1.

Conversion from Traditional Units to SI Units: $1 \mathrm{mmHg} \approx 0.133 \mathrm{kPa}$.

on the recordings at the centre of the mitral ring than on those at the commissure.

\section{Measurements of A2-OS, A2-MO and MO-OS time intervals and statistical'analysis}

The normal values of the A2-MO time interval, corrected for time lag and heart rate, are shown in Table 3. They ranged from 0.060 to $0.110 \mathrm{~s}$ (mean ( \pm SD) $0.081 \pm 0.015$ ).

Patients with mitral stenosis. - The values of A2-OS, A2-MO, and MO-OS time intervals, corrected for time lag and heart rate, are shown in Table 4. A2-OS varied from 0.065 to $0.13 \mathrm{~s}$ (mean $0.106 \pm$ 0.019 ), A2-MO from 0.10 to $0.065 \mathrm{~s}$ (mean $0.040 \pm$ 0.019 ), and MO-OS from 0.055 to $0.075 \mathrm{~s}$ (mean $0.066 \pm 0.012$ ).

Correlations between values of time intervals and severity of stenosis (Fig. 6, Table 4). A2-OS ranged from 0.12 to $0.13 \mathrm{~s}$ (mean $0.125 \pm 0.006$ ) for patients with grade $1,0.09$ to $0.13 \mathrm{~s}$ (mean $0.108 \pm 0.015$ ) for patients with grade 2 , and 0.06 to $0.11 \mathrm{~s}$ (mean $0.090 \pm 0.017$ ) for patients with grade 3 stenosis. A highly significant difference was found between values for grades 1 and 3 $(0.01>P>0.001)$ but a much lesser one between the values for grades 1 and 2 and grades 2 and 3 respectively $(0 \cdot 10>P>0.05)$. As a whole, the greater the severity of the stenosis the lower the values of A2-OS, including, however, an appreciable overlap between two successive groups. A2-MO ranged from 0.045 to $0.07 \mathrm{~s}$ (mean $0.059 \pm$ 0.011 ) for patients with grade $1,0.03$ to $0.07 \mathrm{~s}$ (mean $0.043 \pm 0.014$ ) for patients with grade 2 , and 0.01 to $0.035 \mathrm{~s}$ (mean $0.033 \pm 0.017$ ) for patients with grade 3 stenosis. A highly significant difference was found between the values for any two groups $(0.010>P>0.001)$. MO-OS ranged from 0.05 to $0.075 \mathrm{~s}$ (mean $0.066 \pm 0.011$ ) for patients with grade $1,0.05$ to $0.08 \mathrm{~s}$ (mean $0.065 \pm 0.012$ ) for patients with grade 2 and 0.055 to $0.085 \mathrm{~s}$ (mean 


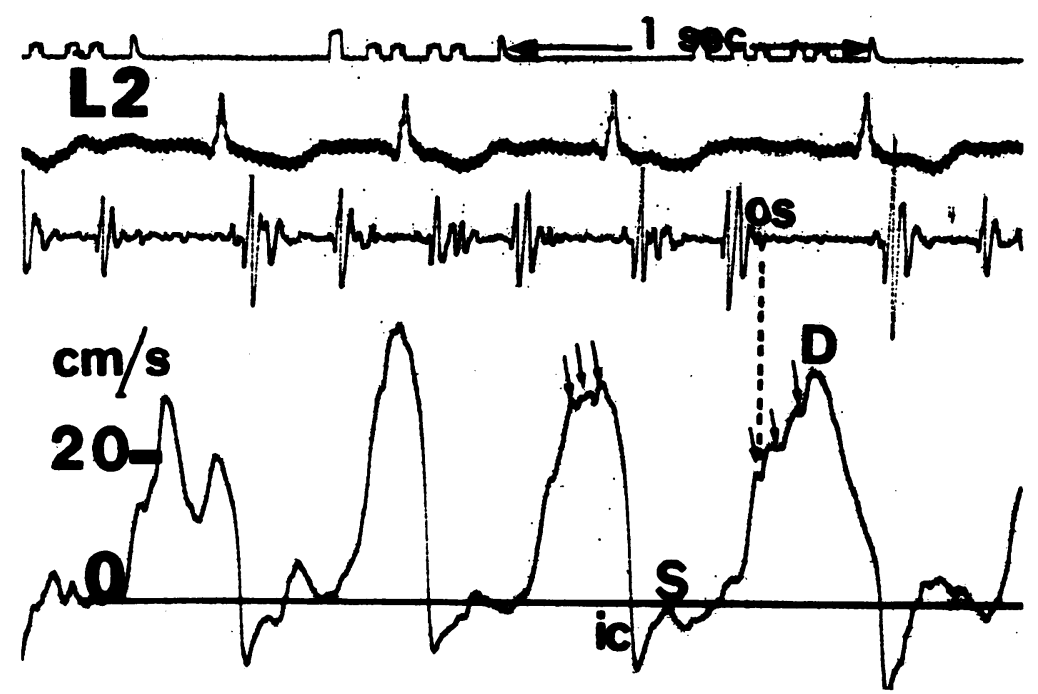

FIG. 3 Time relationship of opening snap in relation to mitral flow velocity trace in patient with mild stenosis.

From top to bottom: ECG lead II, phonocardiogram showing heart sounds and opening snap (low frequency band), flow velocity trace. On ascending limb of $D$ filling wave a first notch appears lining up with opening snap on PCG. Trough of notch lines up with first vibration of $O S$ or lags behind an interval of 0.005 to $0.01 \mathrm{~s}$. After notch and at variable distance from it further notches interrupt end of ascending limb of $D$ wave. (ic=isometric contraction deflection. $S=$ systolic flow wave. $D=$ diastolic filling wave.)

$0.068 \pm 0 \cdot 13)$ for patients with grade 3 stenosis, indicating a complete overlap between all three groups (the statistical analysis indeed showed no significant difference).

Correlations between normal values of A2MO intervals and those of patients with mitral stenosis (Fig 6, Table 4). There was a highly significant difference $(P<0.001)$ between the normal values of A2-MO interval (mean 0.081)

TABLE 3 Values of A2-MO interval (isovolumic relaxation period) in 11 control patients

\begin{tabular}{ll}
$\begin{array}{l}\text { Case } \\
\text { No. }\end{array}$ & $\begin{array}{l}A 2-M O \\
(s)\end{array}$ \\
\hline 16 & 0.080 \\
17 & 0.060 \\
18 & 0.080 \\
19 & 0.060 \\
20 & 0.065 \\
21 & 0.090 \\
22 & 0.090 \\
23 & 0.110 \\
24 & 0.090 \\
25 & 0.075 \\
26 & 0.090 \\
\hline
\end{tabular}

and those of all 15 patients with mitral stenosis (mean $0.040 \mathrm{~s}$ ) of the patients with grade 2 (mean $0.043 \mathrm{~s}$ ) and of the patients with grade 3 stenosis (mean $0.034 \mathrm{~s})$. The difference was less significant $(0.005>\mathrm{P}>0.002)$ between the normal values of A2-MO and those of patients with grade 1 stenosis.

Correlations between values of MO-OS interval and presence or absence of mitral calcification (Table 5). The nine patients with calcification of the mitral valve had a mean value of A2-MO interval of $0.073 \pm 0.008 \mathrm{~s}$, whereas those without calcification had a mean value of $0.056 \pm 0.008 \mathrm{~s}$, indicating a highly significant difference $(P<0.001)$.

\section{Discussion}

\section{Genesis of mitral opening snap}

Attempts to explain the genesis of the opening snap (OS) have established its time relationship with myocardial events, using the jugular venogram and apex cardiogram, and with valve movements, using the echocardiogram of the anterior leaflet or angiograms. The recent advent of mitral flow 


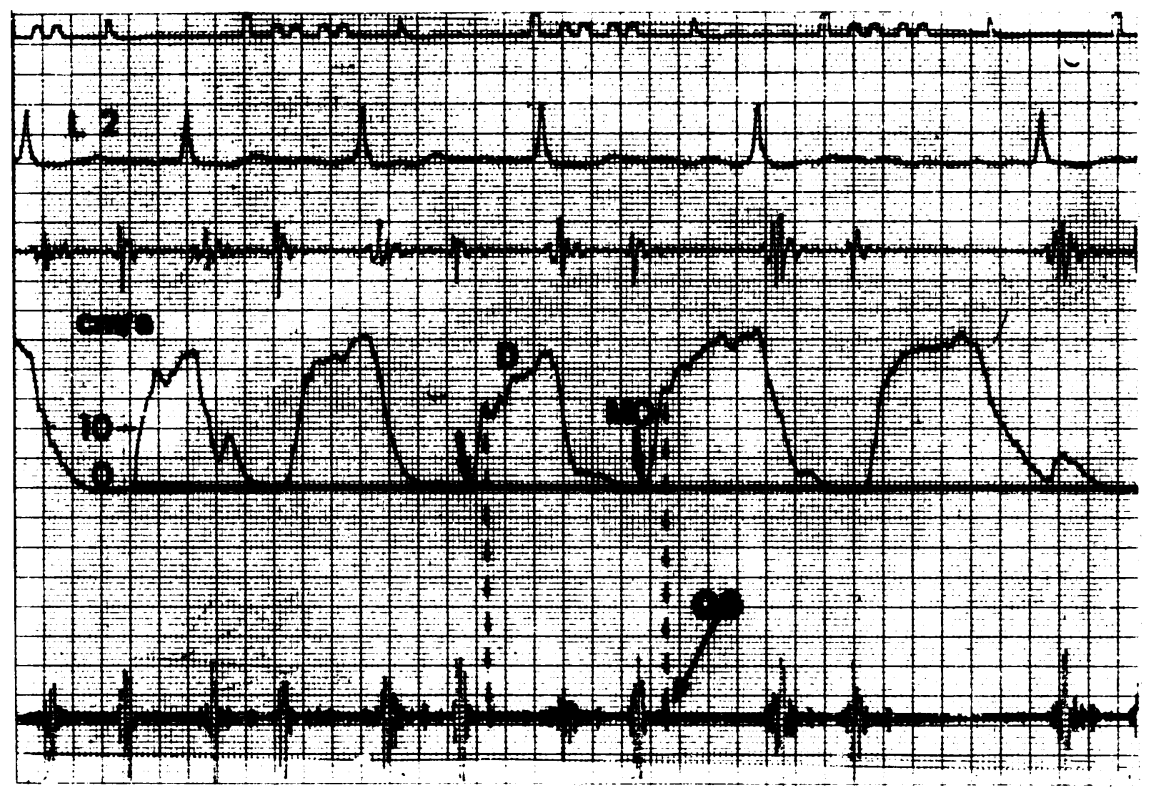

FI G. 4 Time relationship of mitral opening snap with respect to mitral valve flow velocity trace in patient with severe mitral stenosis and atrial fibrillation.

From top to bottom: ECG lead II, phonocardiogram showing heart sounds and opening snap (low frequency band), flow velocity trace, additional high frequency band phonocardiogram. $M O=$ mitral opening point (onset of diastolic filling wave $D$ ). The ascending limb of $D$ wave is interrupted by first notch and thereafter has lesser slope with further small indentations. The summit of notch coincides with first vibration of opening snap, and its trough lags behind by an interval of 0.05 to $0.15 \mathrm{~s}$.

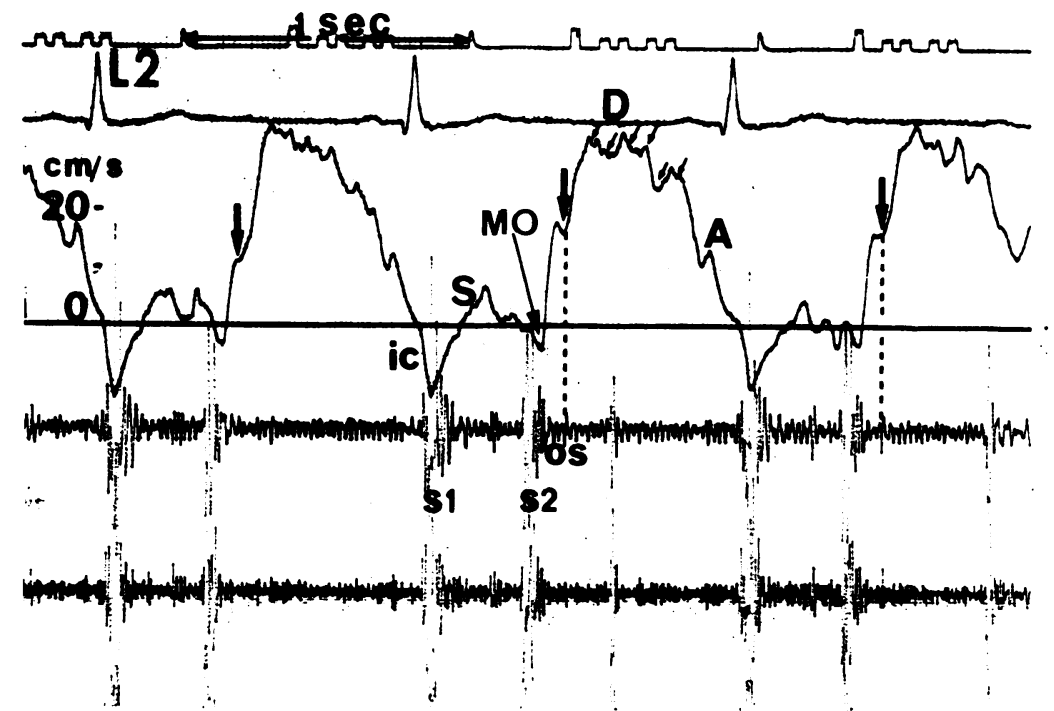

FIG. 5 Time relationship of mitral opening snap with respect to mitral valve flow velocity trace in a patient with mild stenosis in sinus rhythm. $S 1=$ first heart sound. $S 2=$ second heart sound. OS =opening snap. Opening snap lines up with notch interrupting the ascending limb of $D$ wave. Trough of notch occurs $0 \cdot 10 \mathrm{~s}$ after first vibration of snap. 
TABLE 4 Values of A2-OS, A2-MO, and MO-OS time intervals, corrected for time lag and heart rate, correlated with severity of stenosis and presence of mitral calcification in 15 patients with mitral stenosis

\begin{tabular}{|c|c|c|c|c|c|c|c|c|c|}
\hline $\begin{array}{l}\text { Case } \\
\text { No. }\end{array}$ & Rhythm & $\begin{array}{l}\text { Mean } \\
\text { A2-OS } \\
\text { (s) }\end{array}$ & $\begin{array}{l}\text { Group } \\
\text { mean }\end{array}$ & $\begin{array}{l}\text { Mean } \\
A 2-M O \\
\text { (s) }\end{array}$ & $\begin{array}{l}\text { Group } \\
\text { mean }\end{array}$ & $\begin{array}{l}\text { Mean } \\
\text { MO-OS } \\
\text { (s) }\end{array}$ & $\begin{array}{l}\text { Group } \\
\text { mean }\end{array}$ & Calcification & $\begin{array}{l}\text { Grading of } \\
\text { severity }\end{array}$ \\
\hline 1 & AF & $0 \cdot 13$ & \multirow{4}{*}{$\begin{array}{r}0.125 \\
+0.006\end{array}$} & 0.0557 & \multirow{4}{*}{$\begin{array}{r}0.059 \\
\pm 0.011\end{array}$} & $0.075)$ & \multirow{4}{*}{$\begin{array}{r}0.066 \\
\pm 0.011\end{array}$} & +7 & \multirow{4}{*}{1} \\
\hline 2 & AF & 0.12 & & 0.07 & & 0.05 & & 0 & \\
\hline 3 & SR & $0 \cdot 12$ & & 0.045 & & 0.075 & & + & \\
\hline 4 & SR & 0.13 & & 0.065 & & 0.065 & & 0 & \\
\hline 5 & $\mathrm{AF}$ & $0.09 ?$ & \multirow{6}{*}{$\begin{array}{r}0.108 \\
+0.015\end{array}$} & 0.035 & \multirow{6}{*}{$\begin{array}{r}0.043 \\
\pm 0.014\end{array}$} & 0.055 & \multirow{6}{*}{$\begin{array}{r}0.065 \\
\pm 0.012\end{array}$} & 0 & \multirow{6}{*}{2} \\
\hline 6 & $\mathrm{AF}$ & 0.12 & & 0.04 & & 0.08 & & + & \\
\hline 7 & SR & $0 \cdot 10$ & & 0.050 & & 0.050 & & 0 & \\
\hline 8 & $\mathrm{AF}$ & 0.11 & & 0.035 & & 0.075 & & + & \\
\hline 9 & $\mathrm{AF}$ & $0 \cdot 13$ & & 0.07 & & 0.06 & & 0 & \\
\hline 10 & AF & $0 \cdot 10$ & & 0.03 & & 0.07 & & $+J$ & \\
\hline 11 & $\mathrm{AF}$ & 0.11 & \multirow{5}{*}{$\begin{array}{r}0.090 \\
\pm 0.017\end{array}$} & 0.025 ? & \multirow{5}{*}{$\begin{array}{r}0.033 \\
\pm 0.017\end{array}$} & 0.085 & \multirow{5}{*}{$\begin{array}{r}0.068 \\
\pm 0.013\end{array}$} & +7 & \multirow{5}{*}{3} \\
\hline 12 & SR & 0.085 & & 0.010 & & 0.075 & & + & \\
\hline 13 & AF & $0 \cdot 10$ & & 0.03 & & 0.07 & & + & \\
\hline 14 & AF & 0.09 & & 0.035 & & 0.055 & & + & \\
\hline 15 & SR & 0.065 & & 0.01 & & 0.055 & & 0 & \\
\hline
\end{tabular}

$\mathrm{AF}=$ atrial fibrillation; $\mathrm{SR}=$ sinus rhythm. Grading of severity of stenosis: $1=$ mild; $2=$ moderate; $3=$ severe.

TABLE 5 Correlations between MO-OS interval and presence or absence of mitral calcification in 15 patients

\begin{tabular}{rlll}
\hline $\begin{array}{l}\text { Case } \\
\text { No. }\end{array}$ & $\begin{array}{l}\text { Mitral } \\
\text { calcification }\end{array}$ & $\begin{array}{l}\text { MO-OS } \\
(s)\end{array}$ & $\begin{array}{l}\text { Mean } \\
\text { MO-OS }\end{array}$ \\
\hline 1 & + & 0.075 & \\
3 & + & 0.075 & \\
6 & + & 0.08 & \\
8 & + & 0.075 & $0.073 \pm 0.008$ \\
10 & + & 0.07 & \\
11 & + & 0.085 & \\
12 & + & 0.075 & \\
13 & + & 0.07 & \\
14 & + & 0.055 & $\mathrm{P}<0.001$ \\
2 & - & 0.05 & \\
4 & - & 0.065 & \\
5 & $=$ & 0.055 & $0.056 \pm 0.006$ \\
7 & $=$ & 0.050 & \\
9 & - & 0.06 & \\
15 & - & 0.055 & \\
& & &
\end{tabular}

velocity recording by transeptal Doppler ultrasound catheterization of the left heart cavities has provided a new technique for relating phonocardiographic events of the left heart, in particular the mitral opening snap, to instantaneous mitral flow phenomena. The validity of such time relationships quite obviously relies on the accuracy of phonocardiographic and velocimetric determinations. It is therefore appropriate firstly to discuss our technique.

The differentiation of the OS from the pulmonary component of the second heart sound could be easily ascertained by the wide A2-OS interval, which ranged from 0.08 to $0.13 \mathrm{~s}$. In none of the patients was there a right bundle-branch block sufficient to cause such a delay. Even in patients with an A2-OS interval of 0.10 to $0.13 \mathrm{~s}$ the confusion with a third heart sound could be avoided by checking the close time relation of the snap with the $O$ point of the apex cardiogram. Incidentally, the OS always occurred well before the 


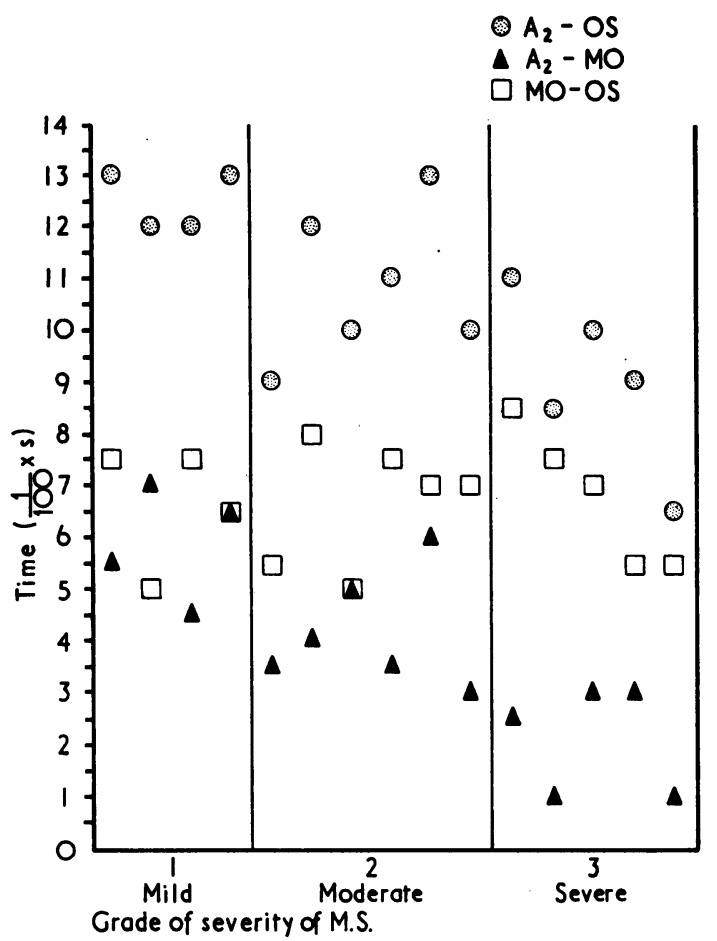

FI G. 6 Diagrammatic relationship between values of $A 2-O S, A 2-M O$, and MO-OS time intervals with grading of severity of stenosis. Values of A2-OS clearly decrease with increasing severity of stenosis. However, there is appreciable overlap between groups 1 and 2 and groups 2 and 3. Groups 1 and 3 and groups 2 and 3 are distinct for values of A2-MO but a small overlap exists between groups 1 and 2. There is complete overlap between all groups for MO-OS values.

peak of the diastolic initial filling $D$ wave of the left ventricle. Since the transmission delay of the phonocardiograph is negligible, determination of $\mathrm{A} 2$ and $\mathrm{OS}$ could be considered as accurate to within $\pm 5 \mathrm{~ms}$.

Yellin and Laniado (Laniado et al., 1973; Yellin et al., 1976) experimentally recording phasic mitral valve flow by means of an electromagnetic cuff flowmeter simultaneously with left atrial and ventricular pressures, demonstrated that the point of crossover of the atrial and ventricular pressure curves was synchronous with the onset of the filling flow wave of the left ventricle-that is, with the beginning of mitral valve opening. Similarly the onset of the velocity flow curve in early diastole may also be considered as representing the true opening of the valve. However, since the trans- mission delay of the Sonicaid BV 135 velocimeter is about $10 \mathrm{~ms}$ (Kalmanson et al., 1972) a correction for this time lag must be made in assessing the timing of the MO point. Accuracy of such a determination may therefore be considered as being within the range of observer's error-that is $\pm 5 \mathrm{~ms}$.

The results of our study allow us to draw the following conclusions.

1) The so-called mitral opening snap occurs after true mitral valve opening, a view expressed long ago (Bouillaud, 1835; Tavel et al., 1965; Fishleder, 1966).

2) The mitral opening snap occurs at a time when the transmitral flow velocity (and consequently also flow rate) has already reached a finite value, and this value is usually well below the peak velocity of the filling wave. This indicates that the opening snap takes place when blood has already begun to flow through the valve-a fact that was denied by Ross et al. (1961), whose cineangiograms failed to disclose any leakage of contrast material through the valve before the OS. The finding that the flow velocity increases steadily before and after the opening notch (ON) shows that the valve is open at the time of the snap and remains open afterwards. This rules out the possibility of a sudden closing of the valve being the origin of the sound, as Rodbard and Libanoff (1972) suggested.

3) The very pattern of the notch (downward deflection or small plateau) synchronous with the OS indicates that blood flow passing through the valve is for a very brief period slowed down (the velocity decreases or ceases to increase), and thereafter continues to increase. Our finding of a brief, transient slowing down of the flow velocity suggests that the latter is most likely to be due to a transient upward displacement of the leaflets towards the left atrium, as if they were suddenly halted by an abrupt tensing of the chordae tendineae-a mechanism in keeping with the general opinion that the opening snap is produced by the sudden tensing of the chordae tendineae at the time of complete excursion of the leaflets. Our observations provide the haemodynamic counterpart of the demonstrations offered previously by studies of mitral valve movements (Ross et al., 1961; McCall and Price, 1967; Friedman, 1970; Millward et al., 1973). These authors concluded that the opening snap occurred at almost exactly the time of total excursion of the valve in patients with mitral stenosis or in situations associated with excess flow passing through the mitral valve.

4) The sound turns out to be a 'tensing' or 'tension' snap rather than a true 'opening' snap, and surely not a 'closing' sound. 


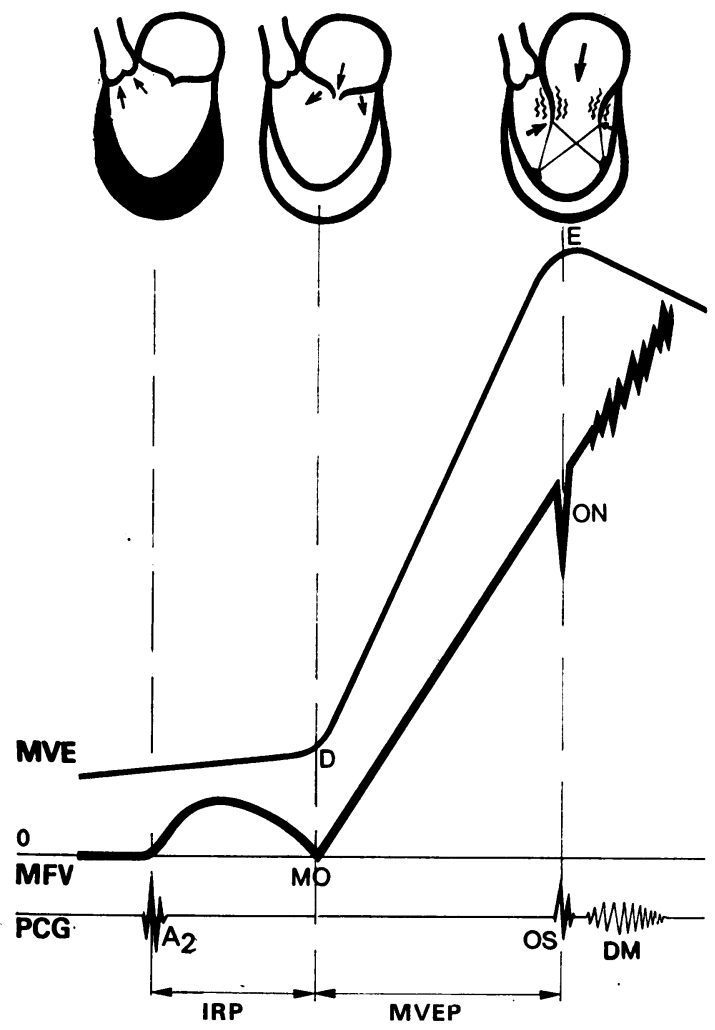

FIG. 7 Schematic early diastolic time relationship between opening snap, echo tracing, and flow velocity curve of mitral valve in patients with mitral stenosis. A2-OS interval is the sum of following two successive components: $A 2-M O$, or true isovolumic relaxation period, and MO-OS, or excursion time of the valve. A2-MO is affected by severity of stenosis (the more severe the latter the shorter A2-MO), whereas MO$O S$ is essentially influenced by presence of calcification, which increases its duration.

Analysis and significance of A2-OS interval. A further finding of our study was that the A2-OS interval does not-even approximately-represent the true isovolumic diastolic relaxation period. Neither does the time interval between $\mathrm{A} 2$ and the $O$ point of the apex cardiogram, which either coincides with or lags behind the OS. In fact, the A2-OS interval consists of the sum of two component intervals (Fig. 7)-namely, the A2-MO, extending from the aortic component of the second heart sound to the time of the MO point on the flow velocity curve, and the MO-OS, extending from the latter point to the time of the opening snap on the phonocardiogram. Since the MO point repre- sents the true beginning of the mitral valve opening, the A2-MO interval can be considered as covering fairly well the true isovolumic relaxation period (IRP) of the left ventricle, and the MO-OS interval as reflecting accurately the time required for the valve leaflets to complete their full excursion from the onset of the valve opening (mitral valve excursion period, MVEP). In fact, the true physiological isovolumic relaxation period (IRP) starts before the aortic closure, and, more precisely, for Wiggers (1952) at the steepening point of the decline of the ventricular pressure curve prior to the trough of the aortic incisura. On the other hand, the aortic component (A2) of the second heart sound does not coincide with the aortic closure but precedes it by as much as 10 to $20 \mathrm{~ms}$ (McCanon, Arevalo, and Meyer, 1964). Finally, the error made by assuming A2 to be the starting point of the IRP may be held to be negligible, and it seems legitimate to consider for clinical purposes that A2-MO represents fairly well the IRP. Not only are the two component intervals clearly distinct in timing but our data further substantiate that their value may vary in relation to the severity of the stenosis or the presence or absence of mitral calcification, thereby inferring that their determining factors are at least partly different.

Normal values and factors in variation of A2-MO time interval (IRP). Arevalo and Sakamoto (1964) measured in 30 patients with a normal left heart the time interval extending from A2 to the point of crossover of the left atrial and ventricular pressures. The values ranged from 0.55 to $0.120 \mathrm{~s}$ (mean $0.81 \mathrm{~s}$ ). These are in keeping with our results-0.060 to $0.110 \mathrm{~s}$ (mean $0.081 \mathrm{~s}$ ) after correction for heart rate-but at some variance from those of Nimura determined by the external Doppler technique-mean 0.067 s \pm 0.011 (Nimura et al., 1968). Furthermore, Weisfeldt et al. (1974), using a right heart bypass preparation in normal dogs, studied the effects of heart rate, stroke volume, and arterial pressure on the duration of the isovolumic diastole. They showed that the latter was shortened by a larger stroke volume due to the rise in left atrial pressure, and insignificantly decreased at higher heart rates with constant stroke volume. In our patients with mitral stenosis, in whom stroke volume, heart rate, and arterial pressure were interdependent, we found that the A2-MO time interval corrected for heart rate decreased with increasing severity of the stenosis (Table 4)-a finding consistent with the well-known earlier occurrence of the point of crossover of the left atrial and left ventricular 
pressure curves with increasing severity of the mitral stenosis. Furthermore, and though our small series of investigations requires confirmation on a larger number of patients, the statistical analysis is in favour of a higher reliability for the A2-MO versus the $A 2-O S$ values in assessing the severity of the stenosis $(0.01>P>0.001$ versus $0.10 P>0.05$ for the two successive grades 1 and 2, and 2 and 3 ).

Factors in variation of MO-OS time interval (MVEP). Table 4 shows the lack of correlation between the MO-OS time interval and the severity of the stenosis. Table 5, on the other hand, shows that when mitral calcification is present, the interval is longer. Conversely, when there is no calcification the MO-OS is shorter. These findings are consistent with Edler's on the value of the speed of the upstroke $\mathrm{DE}$ on the echocardiogram of the anterior leaflet (Fig. 6) (Edler, 1967). In a series of 130 patients with mitral valve stenosis, Edler showed that the average speed of upstroke as measured on the segment $\mathrm{DE}$ of the echocardiogram was $423 \mathrm{~mm} / \mathrm{s}$ in patients without calcification and $174 \mathrm{~mm} / \mathrm{s}$ in patients with much calcification. Since the speed of upstroke is inversely proportional to the duration of the MO-OS interval (duration of excursion of the valve), both studies show that the presence of calcification slows down the velocity of valve opening.

Factors in variation of A2-OS time interval. We can infer from the preceding considerations that the A2-OS time interval is in fact the sum of successively the true isovolumic relaxation period and the mitral valve excursion period. It extends from the onset of the aortic valve closure to the completion of the mitral valve opening in patients with mitral valve disease. In such patients its duration depends on various and complexly interrelated factors, as Weissfeldt has shown-namely, stroke volume, heart rate, arterial pressure-and also on the severity of the stenosis and the presence or absence of calcification. The complexity of these interwoven factors, and in particular the fact, which appears from our data, that they may vary in their effect in the same patient, may largely explain the conflicting statements about the clinical value of the A2-OS interval in mitral stenosis. For example, a severe stenosis with much calcification will be associated with shorter A2-MO interval which is compensated, however, by a longer MO-OS interval. The resulting A2-OS interval will therefore be longer than might be expected from the severity of the stenosis. In other words, the A2-OS interval is related to the severity of the mitral stenosis but it is influenced by so many other factors that a clinical interpretation of it should be made with great caution. These factors must be investigated further before the A2-OS time interval can be used as a reliable index of the severity of mitral valve disease.

\section{Conclusions}

The following conclusions may be drawn from our study.

1) The mitral opening snap occurs only when the valve cusps have completed their full opening excursion. Since the valve cusps take a finite time to open there has been a significant flow through the valve before the opening snap occurs. It corresponds to a small, transient slowing down of the mitral flow velocity.

2) Our findings support the hypothesis of a sudden tensing of the valve abruptly stretched by its chordae tendineae at the time of maximum excursion of the leaflets.

3) The classical A2-OS interval is composed of two successive intervals- the A2-MO, synchronous with the isovolumic relaxation period, followed by the MO-OS, or excursion time of the valve cusps.

4) Both the A2-OS and A2-MO intervals are approximate indexes of the severity of the stenosis, but the A2-MO is the more reliable. On the other hand, the MO-OS interval is irrelevant to the severity of the stenosis and is essentially affected by the presence of mitral calcification, which increases the inertia of the valve cusps.

5) Our analysis of the A2-OS interval and of its components allows us to state that it is essentially different from other intervals such as the isovolumic relaxation period and the $\mathrm{A} 2-\mathrm{O}, \mathrm{O}$ being the lowest point of the apex cardiogram. Apparent close relationships between these different intervals in patients with mitral valve stenosis are therefore purely coincidental. Our findings and the great complexity of the factors that determine the different time intervals explain the conflicting statements in the literature about the reliability of these intervals in assessing the severity of mitral stenosis. The greatest caution in their clinical interpretation is called for.

We thank Dr. D. Tunstall Pedoe (London) for correcting the English translation and for his valuable suggestions.

\section{References}

Arevalo, F., and Sakamoto, T. (1964). On the duration of the isovolumic relaxation period in dog and man. American Heart Fournal, 67, 651. 
Bazett, R. J. (1920). An analysis of the time-relations of electrocardiograms. Heart, $7,353$.

Benchimol, A., and Ellis, J. G. (1967). A study of the period of isovolumic relaxation in normal subjects and in patients with heart disease. American fournal of Cardiology, 19, 196.

Bertin, R.-J. H. (1824). Traité des Maladies du Coeur et des Gros Vaisseaux, p. 176. Baillère, Paris.

Bouillaud, J. B. (1835). Traité Clinique des Maladies du Coeur. Précédé de recherches nouvelles sur l'anatomie et la physiologie de cet organe. Baillère, Paris.

Coulshed, N., and Epstein, E. J. (1963). The apex cardiogram; its normal features explained by those found in heart disease. British Heart fournal, 25, 697.

Delage, B., Delage, F., Lafont, H., and Di Matteo, J. (1971). Etude des phases diastoliques de la courbe mécanique ventriculaire chez le sujet sain au repos. Archives des Maladies du Coeur et des Vaisseaux, 64, 972.

Deuchar, D. C. (1964). Clinical Phonocardiography. English Universities Press, London.

Di Bartolo, G., Nuñez-Dey, D., and Bendezú-Prieto, J. (1962). Left heart studies in mitral stenosis with special reference to intracardiac phonocardiography. American Fournal of Cardiology, 10, 93.

Duroziez, P. (1862). Essai sur les maladies du coeur. Du rythme pathognomonique du rétrécissement mitral. Archives Générales de Médecine, 20, 385.

Edler, K. (1967). Ultrasound cardiography in mitral valve stenosis. American fournal of Cardiology, 19, 18.

Fishleder, B. L. (1966). Exploración cardiovascular y fonomecanocardiografia. La Prensa Medica Mexicana, Mexico.

Forman, J., Fouchard, J., Delzant, J.-F., Varin, G., and Dupérier, C. (1967). Apexocardiogramme et courbes de pression. Archives des Maladies du Coeur et des Vaisseaux, $60,1250$.

Friedman, N. J. (1970). Echocardiographic studies of mitral valve motion. Genesis of the opening snap in mitral stenosis. American Heart fournal, 80, 177.

Kalmanson, D., Bernier, A., Veyrat, C., Witchitz, S., Savier, C. H., and Chiche, P. (1975a). Normal pattern and physiological significance of mitral valve flow velocity recorded by using transseptal Doppler ultrasound catheterization. British Heart fournal, 37, 249.

Kalmanson, D., Toutain, G., Novikoff, N., and Derai, C. (1972). Retrograde catheterization of left heart cavities in dogs by means of an orientable directional Doppler catheter-tip flowmeter. Cardiovascular Research, 6, 309.

Kalmanson, D., Veyrat, C., Bernier, A., Savier, C. H., Chiche, P., and Witchitz, S. (1975b). Diagnosis and evaluation of mitral valve disease using transseptal Doppler ultrasound catheterization. British Heart fournal, 37, 257.

Laniado, S., Yellin, E. L., Miller, H., and Frater, R. W. M. (1973). Temporal relation of the first heart sound to closure of the mitral valve. Circulation, 47, 1006.

Legler, J. F., Benchimol, A., and Dimond, E. G. (1963). The apex cardiogram in the study of 2-OS interval. British Heart fournal, 25, 246.

Luisada, A. A. (1953). The Heart Beat. Hoeber, New York.

Luisada, A. A. (1965). From Auscultation to Phonocardiography. Mosby, St. Louis.

McCall, B. W., and Price, J. L. (1967). Movements of mitral valve cusps in relation to first heart sound and opening snap in patients with mitral stenosis. British Heart fournal, 29, 417.

McCanon, D. M., Arevalo, F., and Meyer, E. C. (1964). Direct detection and timing of aortic valve closure. Circulation Research, 14, 387.
Margolies, A., and Wolferth, C. C. (1932). The opening snap (claquement d'ouverture de la mitrale) in mitral stenosis, its characteristics, mechanism of production, and diagnostic importance. American Heart fournal, 7, 443.

Millward, D. K., McLaurin, L. P., and Craige, E. (1973). Echocardiographic studies to explain opening snaps in presence of nonstenotic mitral valves. American fournal of Cardiology, 31, 64.

Nimura, Y., Matsuo, H., Mochizuki, S., Aoki, K., Wada, O., and Abe, H. (1968). Analysis of a cardiac cycle of the left side of the heart in cases of left ventricular overloading or damage with the ultrasonic Doppler method. American Heart fournal, 75, 49.

Nixon, P. G. F., Wooler, G. H., and Radigan, L. R. (1960). The opening snap in mitral incompetence. British Heart fournal, 22, 395.

Perloff, J. K., and Harvey, W. P. (1962). Auscultatory and phonocardiographic manifestations of pure mitral regurgitation. Progress in Cardiovascular Diseases, 5, 172.

Rappaport, M. B., and Sprague, H. B. (1942). The graphic registration of the normal heart sounds. American Heart fournal, 23, 591.

Rodbard, S., and Libanoff, A. J. (1972). The mitral closing snap. American Heart fournal, 83, 19.

Ross, R. S., and Criley, J. M. (1964). Cineangiographic studies of the origin of cardiovascular physical signs. Circulation, 30, 255.

Ross, R. S., Criley, J. M., and Morgan, R. H. (1961). Cineangiocardiography in mitral valve disease. Transactions of the Association of American Physicians, 74, 271.

Rouchès, F.-J.-M. (1888). Du Claquement d'Ouverture de la Mitrale. Thesis. Faculté de Médecine de Paris, Paris [Steinheil].

Spodick, D. H., and Kumar, S. (1968). Atraumatic measurement of the isometric relaxation period of the left ventricle. Aerospace Medicine, 39, 968.

Tafur, E., Cohen, L. S., and Levine, H. D. (1964). The normal apex cardiogram. Circulation, 30, 381.

Taquini, A. C., Massell, B. F., and Walsh, B. J. (1940). Phonocardiographic studies of early rheumatic mitral disease. American Heart fournal, 20, 295.

Tavel, M. E., Campbell, R. W., Feigenbaum, H., and Steinmetz, E. F. (1965). The apex cardiogram and its relationship to haemodynamic events within the left heart. British Heart fournal, 27, 829.

Weisfeldt, M. L., Scully, H. E., Frederiksen, J., Rubenstein, J. J., Pohost, G. M., Beierholm, E., Bello, A. G., and Daggett, W. M. (1974). Hemodynamic determinants of maximum negative $\mathrm{dP} / \mathrm{d} t$ and the periods of diastole. American fournal of Physiology, 227, 613.

Wiggers, C. J. (1952). Circulatory Dynamics. Grune \& Stratton, New York.

Willems, J. L., De Geest, H., and Kesteloot, H. (1971). On the value of apex cardiography for timing intracardiac events. American fournal of Cardiology, 28, 59.

Yellin, E. L., Laniado, S., Peskin, C. S., and Frater, R. W. (1976). Analysis and interpretation of the normal mitral valve flow curve. In The Mitral Valve : a Pluridisciplinary Approach. Ed. by D. Kalmanson. Proceedings of 1st International Symposium on the Mitral Valve. Publishing Sciences Group, Acton, Mass., U.S.A. (In press).

Requests for reprints to Dr. D. Kalmanson, Service de Cardiologie, Fondation Ophtalmologique A. de Rothschild, 29 rue Manin, 75019 Paris, France. 